\title{
Measuring and optimising employee engagement in Africanised multi-culturally diverse contexts
}

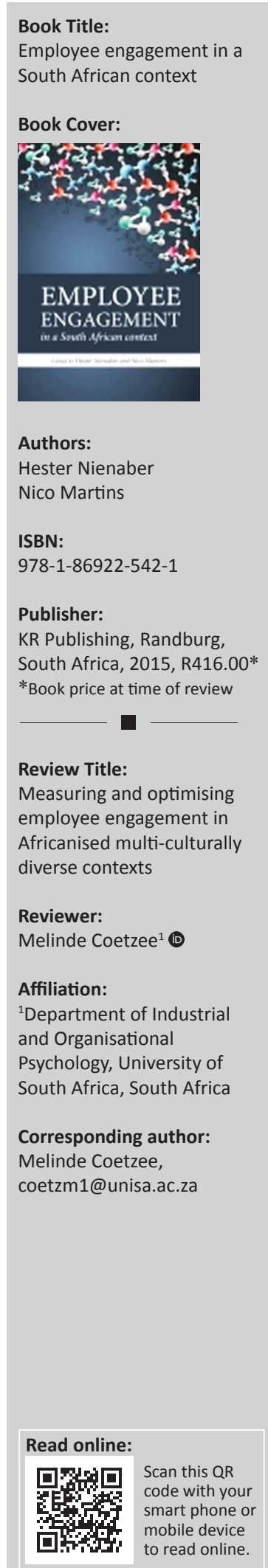

\section{Introduction}

Employee engagement in a South African context edited by Hester Nienaber and Nico Martins is a timely book that contributes valuable perspectives, research and insights on the manifestation of the concept of engagement in the multi-culturally diverse South African and African workplace context. Holly Schiffrin (2016, p. xi) states in the foreword of the book that the benefits of employee engagement for both the employee and the company lie in its contribution to higher job satisfaction, increased productivity, lower turnover, greater customer satisfaction and higher profit. The global and local research literature attests to this viewpoint by providing empirical evidence that alludes to the importance of enhancing employee engagement for business sustainability and competitiveness. The strengths of the book lie in: (1) elucidating the concept from a psychosocial multiple systems level perspective (i.e. clarifying the influence of individual characteristics, interpersonal relationships and the broader environment-cultural context on the manifestation of employee engagement), (2) discussing the application of the concept by means of real-life business case studies and (3) providing a critical evaluation of a South Africa-based measurement model and tool of engagement. The chapter contributions to the book are presented by subject matter experts and practising professionals in the organisational and business field. The text is well written and professionally edited. Employee engagement in a South African context is a valuable contribution to the extant organisational psychology literature on the phenomenon of engagement and may assist leaders and practitioners to better understand the concept, its underlying dynamics and measurement, and its application as a strategic initiative in South Africa- and Africa-based organisations.

\section{Basic premise of the book}

The book anchors the concept of 'engagement' in the positive psychology movement that emerged in the late 1990s with its strong emphasis on human strengths, motives, capacities and optimal functioning. The conceptualisation of the construct is seen to arise from the original work of Kahn (1990). The authors acknowledge the complex nature of the construct, which also makes the measurement of employee engagement more problematic (Nienaber, 2016, p. 26). Based on a critical evaluation of various divergent and inconsistent definitions and theories arising from academics and practitioners of the concept, the book emphasises its focus on 'employee engagement' as an outflow of the relationship between employees' occupational roles and their organisation. Engagement is conceptualised at multiple levels, including the individual (psychological), team and/or unit and organisational and/or environmental levels, all of which alludes to the construct's complexity and the rationale for divergence on the conceptualisation and theoretical underpinnings of the concept. The authors further view employee engagement as a strategic business lever and acknowledge that engagement may manifest differently in different culturally and gender-diverse business contexts. This phenomenon of engagement is illustrated by means of real-life business case studies.

The reliable and valid measurement of employee engagement is another important focus of the book. The research conducted by Nienaber and Martins (Martins, 2016) resulted in the conceptualisation of a theoretical framework and an empirical measure of employee engagement that can be applied in the South African organisational context. The book also emphasises the issue of considering the multicultural sensitive measurement of engagement. Viljoen (2016, p. 101) illustrates this aspect of measurement by elaborating on the notion of multicultural dynamics and discussing the use of the Benchmark of Engagement Questionnaire (BeQ) in various cultural settings. The valid and reliable measurement of employee engagement in culturally diverse

How to cite this book review: Coetzee, M. (2016). Measuring and optimising employee engagement in Africanised multi-culturally diverse contexts. SA Journal of Industrial Psychology/SA Tydskrif vir Bedryfsielkunde, 42(1), a1404. http://dx.doi.org/10.4102/sajip.v42i1.1404 Copyright: @ 2016. The Authors. Licensee: AOSIS. This work is licensed under the Creative Commons Attribution License. 
settings is seen to help the company optimally benefit from organisational engagement efforts.

\section{Structure, content and style of the text}

The structure of the book succeeds in contextualising and conceptualising the construct from an academically sound perspective. Each chapter is unique in that various authors contributed their unique research on the theme in the respective chapter. Introducing the construct of engagement in chapter 1 , the chapters that follow contribute fresh perspectives on the construct by critically evaluating classical and contemporary theory, models and measurements of the construct and their application in the South African and African continent context. The chapters introduce constructs such as engagement as strategy, engagement in relation to trust and leadership, its application in multicultural South African and African contexts and a visionary perspective on engagement as a business intervention. The book succeeds in presenting a balanced academic and practitioner perspective on the construct and provides a sound rationale for the importance of the construct in contemporary organisational contexts. Historical (classical) and current theories and practices as applied in the global, South African and African contexts are adequately evaluated. The empirical grounding of the exposition is sound and coherently presented to satisfy the needs of a scholarly audience. Each chapter is a concise presentation of the relevant theme. Written in a hands-on style, the book may be accessible to both scholars (academics and students) and practitioners. The scholarship is sound and it is evident that the contributors are well acquainted with the literature.

\section{Conclusion}

Although one would not necessarily regard the book as groundbreaking research, it is a novel initiative that provides a succinct integrated perspective of research conducted on the construct and its manifestation in the South African and African context. The latter is a useful contribution to the topic when considering the need for the Africanisation of curricula and research. Each chapter provides evidence of well-researched and substantiated viewpoints of the relevant engagement theme as presented by the relevant author, making the book worthy of consideration by the subject matter expert and the practitioner in the field. The case study applications in multicultural and South African and/or African contexts are useful and new contributions to the subject matter. Employee engagement in a South African context is a valuable contribution to the organisational psychology library from which scholars and practitioners on the African continent will continue to benefit.

\section{References}

Kahn, W.A. (1990). Psychological conditions of personal engagement and disengagement at work. Academy of Management Journal, 33, 92-724. http://dx.doi.org/10.2307/ 256287

Martins, N. (2016). The current state of employee engagement. In H. Nienaber \& N. Martins (Eds.), Employee engagement in a South African context (pp. 53-66). Randburg: KR Publishing.

Nienaber, H. (2016). Engagement and strategy. In H. Nienaber \& N. Martins (Eds.) Employee engagement in a South African context (pp. 21-32). Randburg: KR Publishing.

Nienaber, H., \& Martins, N. (2016). Employee engagement in a South African context. Randburg: KR Publishing.

Schiffrin, H. (2016). Foreword. In H. Nienaber \& N. Martins (Eds.), Employee engagement in a South African context (pp. xi-xiii). Randburg: KR Publishing.

Viljoen, R. (2016). Engagement in diverse workspaces. In H. Nienaber \& N. Martins (Eds.), Employee engagement in a South African context (pp. 101-126). Randburg: KR Publishing. 